DOI: http://dx.doi.org/10.22198/rys.2018.72.a846

Artículos

\title{
Representaciones sociales acerca del narcotráfico en adolescentes de Tamaulipas
}

\author{
Social representations about drug trafficking \\ among adolescents in Tamaulipas
}

\author{
Ariagor Manuel Almanza Avendaño* \\ Anel Hortensia Gómez San Luis** \\ Diego Nahúm Guzmán González ${ }^{* * *}$ \\ José Alfonso Cruz Montes ${ }^{* * * *}$
}

Resumen: el objetivo de este artículo es comprender las representaciones sociales construidas por un grupo de adolescentes del estado de Tamaulipas, acerca del narcotráfico. Se empleó un diseño de estudio de caso intrínseco, y se realizaron entrevistas semiestructuradas para aproximarse al proceso de

\footnotetext{
* Profesor-investigador adscrito al posgrado de psicología de la Unidad Académica de Trabajo Social y Ciencias para el Desarrollo Humano, Universidad Autónoma de Tamaulipas. Centro Universitario campus Victoria. Matamoros s/n, zona centro, C. P. 87000, Ciudad Victoria, Tamaulipas, México. Teléfono: (834) 318 1730. Correo electrónico: manuelalmanzaavendano@ gmail.com

** Autora para correspondencia. Catedrática del Consejo Nacional de Ciencia y TecnologíaUniversidad Autónoma de Tamaulipas. Unidad Académica de Trabajo Social y Ciencias para el Desarrollo Humano. Universidad Autónoma de Tamaulipas, campus Victoria, Ciudad Victoria, Tamaulipas, México. Correo electrónico: anelgomezsanluis@gmail.com

*** Pasante de la carrera de psicología. Unidad Académica de Trabajo Social y Ciencias para el Desarrollo Humano, Universidad Autónoma de Tamaulipas. Correo electrónico: aeroajalktraz@, gmail.com

**** Pasante de la carrera de psicología. Unidad Académica de Trabajo Social y Ciencias para el Desarrollo Humano, Universidad Autónoma de Tamaulipas. Correo electrónico: alfonsomontes27@gmail.com
} 
construcción de su representación social. Para analizar el contenido temático se utilizó el programa MAXQDA 11. Los resultados muestran que los adolescentes consideran al narcotráfico como una actividad delictiva, que se ha diversificado para incluir otros delitos asociados con la violencia y el daño a los demás. Es un estudio exploratorio y, pese al número reducido de participantes, recupera las voces de los adolescentes inmersos en comunidades donde hay narcotráfico, sin que participen directamente en él, también da cuenta de que la incorporación de los jóvenes en el narcotráfico se limita cuando lo perciben como un delito, y elaboran su identidad en contraposición a él.

Palabras clave: narcotráfico; adolescencia; delincuencia; violencia; psicología social; psicología de grupo; Tamaulipas.

Abstract: the aim of this article is to understand the social representations constructed by a group of adolescents of the state of Tamaulipas about drug trafficking. An intrinsic case study design was used and semi-structured interviews were conducted in order to explore the social representation construction process. For the purpose of analyzing the thematic content the MAXQDA 11 program was used. The results show that adolescents consider drug trafficking as a criminal activity that has become more diverse, including other crimes associated with violence and harming others. This is an exploratory study, which, notwithstanding the small number of participants, recovers the voices of the adolescents immersed in communities where drug trafficking is prevalent, without participating directly in it. Likewise, it explains that young people's involvement in drug trafficking decreases when they perceive it as a crime, developing their identity as opposed to it.

Keywords: drug trafficking; adolescence; crime; violence; social psychology; group psychology; Tamaulipas. 
Recibido el 15 de septiembre de 2016. Aceptado el 26 de abril de 2017.

\section{Introducción}

Tamaulipas ocupa una posición estratégica para los grupos de narcotraficantes, pues la amplia frontera con Estados Unidos facilita el tráfico de drogas desde América del Sur, la península de Yucatán, el golfo de México y la región del Pacífico (Guerrero 2010). Hay dos organizaciones delictivas en conflicto, que han estado presentes en el estado durante la década 2007-2017: el Cártel del Golfo, cuya estructura de mando es "tradicional", y suele evitar la confrontación con las fuerzas armadas; y Los Zetas, de tipo militar, que refuerza la disciplina entre sus miembros mediante la violencia, participa en otras actividades delictivas, tiene mayor presencia en el territorio nacional y ataca a las fuerzas armadas en forma deliberada (Astorga 2012).

A finales de los años noventa, Los Zetas surgieron para proteger al Cártel del Golfo, pero se independizaron alrededor de 2007 y se expandieron hacia diversas entidades (Ravelo 2013), y desde 2010 los dos grupos mantienen un enfrentamiento en Tamaulipas, Nuevo León, Coahuila y la región norte de Veracruz. Ambas agrupaciones cuentan con células autónomas que luchan entre sí; las vinculadas con Los Zetas participan también en secuestros y extorsiones, y se estima que en Tamaulipas cuentan con 42 células, el mayor número en el país (Guerrero 2016).

Al parecer, el Cártel del Golfo está dividido en dos grupos principales (las pandillas del cártel y la red de los Velázquez), y Los Zetas se encuentran en un proceso de balcanización, debido a la captura de mandos importantes y conflictos internos que han favorecido la disputa por territorios de organizaciones rivales, en diversas zonas del país (Stratfor Global Intelligence 2015a, b). Debido a la presencia de este conflicto, la ciudadanía considera que el narcotráfico no sólo se vincula con el tráfico de drogas, sino también con la violencia en el espacio público, la cual en los últimos años ha jugado un papel fundamental en su mantenimiento y expansión. 
Los adolescentes que viven en Tamaulipas están expuestos de manera cotidiana al narcotráfico en sus comunidades, y en el estado se ha reportado un consumo elevado de marihuana y cocaína (Secretaría de Salud 2008), por lo que el estudio y prevención del fenómeno son aspectos prioritarios e impostergables. De ahí que el propósito del presente estudio sea conocer las representaciones sociales acerca del narcotráfico, construidas por adolescentes que habitan en una localidad de esta entidad, a fin de comprender la manera en que le otorgan sentido a este fenómeno y se posicionan ante él.

Mediante la perspectiva metodológica de las representaciones sociales, la contribución principal de la investigación se centra en buscar la comprensión del narcotráfico en los adolescentes de Tamaulipas, un sector de la población que no se ha estudiado y cuyo contexto es vulnerable. Además, en términos de prevención, aproximarse a las representaciones sociales de los adolescentes que habitan en contextos con gran presencia de narcotráfico permite conocer su grado de aceptación, las creencias y valoraciones sobre él, para identificar el riesgo que corren de ser incorporados por las organizaciones delictivas, y definir los elementos que les permitan distanciarse de esta actividad.

\section{La organización del narcotráfico}

El narcotráfico representa la principal economía criminal y el motor financiero de la criminalidad organizada en América Latina (Pontón 2013); requiere dos tipos de redes para su funcionamiento: a) las encargadas de la producción, la distribución y la comercialización de las drogas, así como del lavado de dinero y la reinversión de las ganancias y b) las responsables de la apropiación y defensa de territorios, puntos y rutas estratégicas, así como de la seguridad de los miembros; de la coerción, mediante la fuerza y el soborno, de autoridades, grupos rivales y la ciudadanía, para trasgredir la ley y realizar acciones para su beneficio (extorsión, actos terroristas, control armado o desplazamiento forzado); y de las labores de corrupción, para penetrar estructuras políticas locales, regionales o nacionales, y manipular la ley y las instituciones en favor de sus intereses (a través de la compra de votos o el acceso directo al poder público) (Raffo y Segura 2015). 
Dichas redes internas se mantienen principalmente por vínculos de "confianza", en especial a través del parentesco y la amistad con los miembros de mayor jerarquía, pero como éstos son escasos, la corrupción permite que las organizaciones se inserten en los sistemas financieros, en las empresas privadas o en la administración pública y las fuerzas de seguridad y de procuración de justicia. Sin embargo, también disponen del uso ilegítimo de la violencia para intimidar a la ciudadanía, a grupos rivales o a las instituciones, así como para castigar a sus integrantes (Silva de Soussa 2004).

Si bien el cultivo o la producción de drogas no es condición para que las tasas de homicidio sean altas, sí existen variables como la presencia de las áreas estratégicas y las que están en disputa, como sucede en Tamaulipas, que pueden manifestar mucha violencia (Cubides 2014). Según Bataillon (2015), parece que los actores del narcotráfico, con tal de tener éxito realizan cualquier acción, aun cuando trasgredan la ley, sobre todo cuando las instituciones son deficientes o ante la ausencia de ellas. En este sentido, existen paralelismos entre el narcotráfico y el capitalismo, puesto que ambos enfatizan el individualismo, se benefician del debilitamiento del Estado, promueven la ganancia inmediata antes del trabajo, la inclusión a través del acceso a bienes de consumo, además de subestimar la vida humana, ya sea por la explotación o la muerte (Azaola 2012).

La articulación y el mantenimiento de las redes del narcotráfico requieren de una división de funciones entre los miembros de las organizaciones; las que operan en Tamaulipas cuentan con redes de informantes que incluyen a civiles y a miembros de las fuerzas de seguridad, quienes también brindan protección a traficantes al menudeo. Además, poseen una estructura interna que incluye a los actores siguientes: a) los "halcones" o vigilantes de las zonas de distribución; b) las "ventanas" o adolescentes que alertan sobre la presencia de autoridades o sospechosos; c) los encargados de los puntos de venta de drogas; d) los responsables de brindar seguridad; e) los "expertos" en intercepción de llamadas, seguimiento de vehículos o secuestros y ejecuciones; f) los contadores, responsables de las finanzas y de pagar los sueldos a los integrantes de la organización y a los servidores públicos vinculados con ella y g) los "jefes", que está a cargo de las plazas y de los "sicarios", para su seguridad personal (Astorga 2007; Ravelo 2013). 
Además de los actores mencionados, Silva de Soussa (2004) identificó también a otros: a) los gerentes o administradores de la venta; b) los vendedores; c) los empacadores de la droga; d) los responsables de la custodia y distribución de armas; e) los encargados del lavado de dinero (quienes mantienen negocios legales o compran bienes con el dinero del narcotráfico, o lo manejan en sus cuentas corrientes); f) los contactos o negociadores (compran y trasportan la droga que se comercializa); g) los intermediarios, realizan la compraventa de dólares en el mercado negro o el envío ilegal de dinero al extranjero; h) los encargados de recibir y trasportar vehículos robados; i) los almacenistas de grandes cantidades de droga y j) los falsificadores y receptores de documentos robados.

Además de establecer redes de varios tipos, que requieren una división especializada de las actividades del narcotráfico, las organizaciones y sus miembros se incorporan a la vida cotidiana de los contextos locales en donde operan. Lo pueden hacer de manera violenta, a través de actos de intimidación y horror que promueven el silencio, el control o el sometimiento (Reguillo 2012); o de forma más sutil, por medio de la incursión en la economía local, ya sea mediante el lavado de dinero o la solicitud de bienes y servicios para sus miembros (Bataillon 2015).

Las organizaciones del narcotráfico también tratan de influir en cómo son percibidas por la ciudadanía, con la construcción de obras en las comunidades, la entrega de despensas, las celebraciones, las narcomantas u otro tipo de mensajes y el control de los medios de comunicación, así como por la forma en que sus miembros se muestran o comportan en el espacio público. Ante esta multiplicidad de mensajes, los residentes construyen un conocimiento de sentido común, que les permite entender su actividad, asumir posiciones ante el fenómeno e incluso orientar sus acciones en el espacio social.

\section{Construcciones locales acerca del narcotráfico}

Escalante argumenta que en el discurso oficial del gobierno mexicano acerca del narcotráfico, "la violencia se explica mediante un relato casi abstracto, estereotipado, reiterativo e imposible de verificar, en 
que los 'cárteles' compiten entre sí, y son en realidad los únicos actores, en todo caso los únicos actores con iniciativa, y por otra parte las víctimas permanecen anónimas, aunque más o menos explícitamente asociadas a la delincuencia" $(2012,40)$. Una consecuencia de este discurso, que pretende ofrecer una imagen homogénea, eliminar ambigüedades y explicar lo que sucede respecto al narcotráfico, es que los sucesos relacionados con éste son descontextualizados y desaparece su significado concreto, pues se dejan de ver como acontecimientos que rompen el orden habitual de las comunidades (Escalante 2012). Sin embargo, en las localidades donde está asentado emerge una polifonía de discursos, que pueden coincidir o contrastar con el oficial, y permiten identificar cómo los grupos sociales se posicionan ante dicho fenómeno (Padilla 2012).

De acuerdo con Silva de Soussa (2004), en las comunidades existe un ethos local, que constituye un estilo de vida aprobado y una estructura de la realidad, que da sentido al mundo de los actores de dichos contextos. Debido a esto, a las actividades relacionadas con el narcotráfico se les puede dar más legitimación en donde la actuación de los actores locales se aleja de los parámetros institucionales establecidos por el Estado, por ejemplo donde hay negocios ilícitos, se rechaza a la policía o la vida se rige con base en códigos de honor (que se manifiestan cuando no se delatan negocios ilícitos ni se recurre a los agentes del Estado para la resolución de conflictos). No obstante, en las ciudades donde opera el narcotráfico, si bien es posible que en ciertos espacios y grupos se pueda aceptar su presencia, también suele haber rechazo abierto o ambivalencia.

Mendoza (2008) señaló que en una comunidad de Sonora la gente comenzó a aceptarlo como parte de la vida del lugar, y justificarlo principalmente por el desempleo o su papel en la economía local. Los residentes no se sienten amenazados por su existencia, y conviven de forma un tanto cómoda con personas conocidas que se dedican a él. Y, además de considerarlo como un "mal necesario", en especial los jóvenes se sienten atraídos por la narcocultura o incluso, desde que son niños o adolescentes, expresan el deseo de convertirse en narcotraficantes.

La aceptación del narcotráfico coexiste con el rechazo, debido a lo siguiente: a) la percepción de que se realiza un "envenenamiento", 
a través de la droga; b) la "decadencia moral", asociada al tráfico de drogas y otras actividades relacionadas; c) la forma de obtener "dinero fácil" y "dinero sucio" o d) la violencia y la inseguridad que produce. Los habitantes de la comunidad más cercanos al fenómeno no emplean términos genéricos como "narcotraficante", sino "mafioso" (que implica una evaluación moral de la actividad, y señala la pertenencia a una agrupación que provee reconocimiento y protección) o "mañoso" (que se refiere a una persona que hace las cosas de manera poco convencional, y a la vez expresa una forma de devaluación), además de identificar a ciertos personajes con funciones especializadas, como los "burreros" (quienes cruzan droga a través de la frontera) o los "moteros" (que distribuyen marihuana) (Mendoza 2008).

En un estudio realizado en Tijuana, donde la presencia del Cártel de Tijuana ha sido histórica, los jóvenes universitarios coinciden en que el narcotráfico es una actividad delictiva, rentable, pero riesgosa, y que constituye un problema de seguridad pública. Sin embargo, también se identificó una ambivalencia hacia el fenómeno, puesto que había grupos que lo "satanizaban" y otros para los que era "indiferente". Para los primeros, el narcotráfico constituye una red criminal que comercia con la enfermedad y la muerte; comete crímenes contra la humanidad; sus miembros son criminales "desalmados"; tienen un estilo de vida despreciable; constituye un "cáncer social", y sienten "repulsión” o "miedo”. En cambio, para los del segundo representa un negocio que satisface una demanda, y se debe legalizar, a sus miembros se les percibe como empresarios ilegales, lo asocian con el éxito social y una opción laboral, y su actitud principal es la indiferencia (Ovalle 2005).

En otro estudio realizado con jóvenes universitarios de Culiacán, donde opera el Cártel de Sinaloa, el narcotráfico se asocia con las consecuencias sociales que genera, sobre todo con las adicciones, el tráfico y el consumo de drogas; se percibe como un trabajo, además de encontrarse ligado íntimamente con la violencia, en términos concretos con las matanzas, los asesinatos, las armas, las balaceras y la delincuencia. También se identifican beneficios económicos, asociados a la venta, el comercio y el lavado. Asimismo, hay una valoración positiva del estilo de vida asociado con él, vinculado a los lujos, camionetas, tener mujeres, propiedades o artículos de consumo. Así, en 
este contexto se observa una valoración ambivalente del narcotráfico, que fluctúa entre la idealización de sus beneficios económicos y el estilo de vida, relacionado con la percepción de sus consecuencias sociales; aunque cabe mencionar que los varones enfatizaban la valoración positiva, en contraste con las mujeres (Reyes-Sosa et al. 2015).

La vinculación entre el narcotráfico y la violencia es lo que promueve su rechazo entre los habitantes de las comunidades. En un estudio con jóvenes en Matamoros se encontró que la violencia del narcotráfico ha instigado la construcción de un estilo de vida, basado en el miedo y la inseguridad, donde la vivienda se trasforma en un "refugio de guerra" (pues no se debe salir a ciertas horas y se tiene que contar con los recursos suficientes), por el temor a que sus cuerpos sean levantados, castigados o desaparecidos (De la O y Flores 2012).

En Ciudad Juárez también se mostró cómo la violencia asociada al narcotráfico incide en diversos tipos de capital en las familias, como en el económico, por los robos patrimoniales, el cierre de negocios o los horarios inestables debido a la violencia, o la decisión de las madres de familia de no trabajar para cuidar de sus hijos. El capital social se ve menguado por la dificultad de convivir y recurrir a las redes de familiares y amigos, debido a las distancias o a vivir en zonas peligrosas; al mismo tiempo, la desconfianza y el temor a exponerse a la violencia generan aislamiento.Y también el capital cultural resulta disminuido, debido a que la mayor parte del tiempo libre se vive refugiado en casa, en lugar de desarrollar habilidades prácticas en la calle o acudir a eventos culturales (Hernández y Grineski 2012).

Los estudios previos se dirigieron a comprender los posicionamientos de jóvenes universitarios y adultos en general frente al narcotráfico, sin embargo, se ha dejado de lado a un grupo vulnerable: los adolescentes. Azaola (2012) señaló la presencia de un proceso de "desafiliación acelerada" de los jóvenes, que les ha favorecido a las organizaciones del narcotráfico para reclutar adolescentes cuya calidad de vida es precaria y muy vulnerable. Dicha situación está ligada a la falta de condiciones estructurales para que se incorporen en forma digna a la sociedad; la falta de un plan y de políticas educativas, de salud y empleo para acompañarlos, así como la desconfianza en la po- 
lítica formal, que se ha compensado con la valoración e incorporación a prácticas fuera de la legalidad.

Los estudios con adolescentes son escasos, debido a la censura de las instancias oficiales, al contexto local que representa peligro, los riesgos latentes al realizar trabajo de campo y a los aspectos éticos relacionados con la minoría de edad, pues son factores que dificultan la investigación con adolescentes en contextos de narcotráfico. Y, a pesar de que es posible suponer que hay algunas similitudes con los trabajos realizados entre éstos y los de jóvenes, tales semejanzas no se deben dar por sentadas. Es necesario conocer las diferencias entre ambos grupos, pues las acciones de prevención deben responder de manera específica a cada uno. La teoría de las representaciones sociales constituye una propuesta para aproximarse a la perspectiva de los adolescentes.

\section{Acerca de la teoría de las representaciones sociales}

La representación social es "un conjunto de pensamientos y emociones expresados en la conducta verbal y abierta de actores, que constituye un objeto para un grupo social" (Wagner et al. 1999, 95). Esto implica que en las conversaciones y acciones cotidianas, las personas atribuyen significados a los objetos sociales para convertirlos en parte del mundo social del grupo, es decir, parten de concepciones compartidas de los objetos para comunicarse y coordinar sus acciones en la cotidianidad. La representación social forma una descripción estructurada y multidimensional de un objeto relevante o significativo para la existencia de un grupo, como en este caso es el narcotráfico. Dicha descripción es una elaboración simbólica que otorga al objeto un significado social particular para un grupo. Las representaciones también se manifiestan a través de imágenes o metáforas básicas, que comunican la experiencia afectiva de los sujetos hacia el objeto social. Y tienen, simultáneamente, un carácter evaluativo, debido a que los objetos sociales inciden en el bienestar de los sujetos. Dicha evaluación orienta sus prácticas, en términos de acciones verbales y corporales relacionadas con el objeto (Wagner y Hayes 2011). 
Fenómenos como el narcotráfico interrumpen la vida social, ya que pueden ser amenazantes e imprevistos. Los grupos sociales requieren afrontarlos tanto material como simbólicamente; en el segundo caso, recurren a un proceso de anclaje, lo cual implica nombrarlo y atribuirle características para entenderlo, a partir de términos familiares y representaciones previas. Conforme aumenta la actividad discursiva en relación con el objeto en la cotidianidad, ya sea mediante conversaciones o por los medios de comunicación, los grupos llevan a cabo un proceso de objetivación, en que el objeto es representado de una forma específica, a través de una imagen, una metáfora o un símbolo, que capta su esencia y permite que se vuelva familiar y parte del conocimiento de sentido común. La objetivación depende de las condiciones sociales y características del grupo que elabora la representación (Wagner et al. 1999).

Este nuevo objeto social de representación se constituye a partir de la elaboración discursiva progresiva y continua de un sistema de significados y de la acción, basada en la forma en que interpretan y se comunican acerca del objeto. Por otro lado, al compartir una representación social, un grupo mantiene una identidad, lo cual promueve la afiliación y la coherencia, además de establecer las condiciones para aceptar o rechazar representaciones nuevas. Los niños son socializados de acuerdo con las representaciones que circulan en el grupo social en el que nacen, y en un espacio específico (Wagner et al. 1999). Sin embargo, éstas se pueden trasformar a partir de la experiencia directa con el fenómeno, el proceso de desarrollo y la vinculación con otros grupos más allá de la familia, en especial en la adolescencia.

\section{Método}

Aquí se realizó un estudio exploratorio, desde la teoría de las representaciones sociales, a fin de comprender el conocimiento de sentido común que construyen los adolescentes varones de contextos urbanos de un municipio de Tamaulipas acerca del narcotráfico (por cuestiones de seguridad y protección se omitieron los nombres de los participantes e investigadores). Se empleó un diseño de estudio de caso intrínseco para lograr una mejor comprensión (Gundermann 2008); 
se configuró por el tipo de población participante: adolescentes que viven en una comunidad con presencia de narcotráfico.

La muestra obtenida fue homogénea propositiva (Tong et al. 2007), de acuerdo con dos criterios de inclusión: ser adolescente y vivir en Tamaulipas, y fue contactada a través de informantes clave (docentes de una escuela secundaria), que conocen a los adolescentes y las ocupaciones de sus padres, así se garantizó que éstos no realizaran actividades dentro del narcotráfico, por cuestiones éticas y de seguridad para todos. El tamaño de la muestra se definió con el criterio de saturación teórica; después se explicaron los objetivos, y se obtuvo el consentimiento informado para la participación de los padres y los adolescentes. En ninguna etapa del proceso de la entrevista se solicitaron datos que permitieran identificar a los participantes, y las grabaciones se eliminaron tras haberlas trascrito.

\section{Participantes}

En el estudio participaron diez adolescentes varones de tercer grado de secundaria, entre los 14 y 15 años. Siete de ellos vivían con ambos padres y tres sólo con la madre o con sus hermanos. Asimismo, los padres de siete trabajaban como profesionistas; tres tenían gustos relacionados con el narcotráfico (series, películas o narcocorridos) y sólo dos habían tenido una experiencia directa relacionada con el fenómeno.

\section{Medios de exploración}

Las entrevistas semiestructuradas se realizaron por medio de una guía, donde se abordaron los temas siguientes: a) gustos y pasatiempos del adolescente; b) el concepto del narcotráfico; c) términos relacionados con el narcotráfico; d) actores del narcotráfico y características asociadas (actividades, formas de vestir, hablar y divertirse); e) motivos para ingresar al narcotráfico y f) consecuencias positivas y negativas del fenómeno. Las entrevistas se llevaron a cabo en forma privada dentro de instituciones educativas. 


\section{Análisis de los datos}

Las entrevistas fueron audiograbadas y trascritas para analizarlas con el software MAXQDA, versión 11. Mediante el programa se elaboraron notas, y se construyeron códigos vinculados con los ejes de la entrevista, y luego éstos se agruparon en categorías principales que dan cuenta de los contenidos centrales de su representación social. Las categorizaciones se realizaron en forma independiente por dos de los investigadores, como parte del proceso de triangulación de datos.

\section{Resultados}

Los términos para el narcotráfico

Los participantes utilizan el término tradicional "narcotráfico" para referirse al fenómeno, y algunas formas derivadas, como "narcos" o "tráfico de drogas". Sin embargo, también emplean el nombre de las organizaciones de mayor presencia en la localidad, "Zetas" o la forma en que se les nombra comúnmente, "el cártel”. Los adolescentes además usan vocablos como "delincuencia" o "crimen organizado", lo cual hace alusión a la trasformación de las organizaciones al pasar del tráfico de drogas, como actividad principal, hacia la comisión de otros actos ilícitos como la extorsión o el secuestro.

\section{Las actividades del narcotráfico}

Los participantes consideran al narcotráfico como una organización para el tráfico, venta o "traer" droga, tanto en México como en cualquier parte del mundo. Sin embargo, esta concepción coexiste con la noción de que también comete delitos como robar, matar, traficar órganos, dedicarse al comercio ilícito o cualquier cosa que se tenga que hacer para que "el grande (el capo) consiga lo que quiere". Otro elemento importante para el contexto local es considerar al narcotráfico como una organización de "personas malas" que le hacen daño a la gente, lo cual incluye la evaluación moral de los actores, a quienes 
se les nombra como los "malos". Esta representación de los adolescentes puede implicar una ilusión de seguridad para ellos, pues si el narcotráfico reúne a personas malas, y ellos no se definen como tales, entonces no se verán involucrados. Además, esta representación social les permite vivir cotidianamente en relativa calma, sin sospecha o zozobra por su posible incursión en el narcotráfico. Aunado a esto, la representación del narcotráfico como una organización de personas malas muestra un discurso dicotómico que, si bien reduce la complejidad del fenómeno, minimiza simbólicamente el riesgo real y latente que enfrentan los adolescentes, al ser candidatos potenciales para participar en actividades delictivas.

\section{Los actores del narcotráfico}

Respecto a los actores del narcotráfico, los participantes identifican a los actores de rango bajo, como "halcones o mulas" (trasportadores), o también mencionan términos más genéricos como "personas malas o narcotraficantes" y, en menor medida, a los "sicarios o capos", de quienes es probable que tengan menos referentes concretos en la cotidianidad.

Los adolescentes señalan que los halcones se dedican principalmente a funciones de "vigilancia, reporte o alerta"; y suelen estar "sentados o parados en un lugar, con un radio o celular". Algunos consideran que por su actividad pueden estar "nerviosos". Mencionan que "hablan con groserías" o emplean un "código militar para comunicarse", aunque para otros son "callados o hablan como la gente normal". Los halcones suelen "vestir como cualquier persona y tratan de pasar desapercibidos"; aunque también se menciona que "usan ropa de marca o incluso visten de ropa oscura". Consideran que su apariencia física es "negativa o fea", que pueden "tener cicatrices, estar sudorosos o tatuados". Los adolescentes perciben que los halcones se divierten "consumiendo drogas, tomando alcohol, rentando grupos musicales, haciendo fiestas o con mujeres"; aunque algunos consideran que el "ganar dinero sucio o matar" es también una "forma de diversión" para ellos. Sin embargo, a la vez se percibe que "ya no pueden divertirse", debido a su actividad. 
En cuanto al actor genérico, considerado como "narcotraficante", señalan que se encargan de "mover la droga, planear y organizar", e incluso dedicarse a otra cosa. Pueden hablar de forma común, "visten como cualquier persona" para no llamar la atención, aunque también se menciona que visten en forma más moderna o diferente, o que "se tapan la cara". Su apariencia "no da confianza", tienen "mal aspecto físico o están débiles y usan piercings". Se llaman entre sí "por apodos, traen mochilas, hablan en radio y andan en camionetas". En cuanto a su diversión, también consideran que "consumen drogas, alcohol, hacen fiestas, están con mujeres", pero que a la vez hacer "maldades" o cumplir su objetivo es algo que les brinda placer.

Otros actores menos centrales en la representación social de los participantes son las "mulas", quienes se dedican a "trasportar droga", hablan "en forma normal" y se divierten "comprando cosas", aunque no saben cómo se visten. También identifican a los "sicarios", cuya función es secuestrar o "matar gente inocente”, así como a "gente de otros cárteles". Se caracterizan por andar "encapuchados, en camionetas, portando armas, con chaleco antibalas", y pueden "vestir de negro o como gente civil". Se divierten "comprando droga, ganando dinero sucio o matando gente".

Las "personas malas" se dedican a matar y traficar drogas, pero no las caracterizan por su forma de hablar, vestir ni divertirse. A los denominados "zetas", los describen como los que "hablan en forma grosera, andan en camionetas negras y visten de manera informal"; se divierten consumiendo alcohol y drogas. También está el "capo”, el jefe de la zona, "disfruta lo que hace y recibe respeto", sus actividades principales son "dar órdenes y planificar". Puede vestir "de manera formal o incluso en mezclilla", habla "en forma grosera, también en clave", aunque no hay una cercanía con este personaje en la cotidianidad. Los participantes consideran que se divierte "tomando, drogándose o haciendo fiestas".

\section{Motivos para ingresar al narcotráfico}

Los participantes señalaron la "búsqueda de dinero" y la "falta de oportunidades educativas o económicas" como los motivos princi- 
pales para dedicarse al narcotráfico, que se vinculan con la ausencia de apoyo por parte del gobierno. El aspecto económico también está relacionado con la necesidad de "sacar adelante a su familia". A la vez mencionan que pueden recurrir a esta actividad como una "forma de adquirir poder". Un último elemento que matiza este aspecto es la "búsqueda de dinero fácil", lo cual asocian con la flojera, no querer estudiar o el deseo de darse lujos.

A pesar de la diversidad de motivos, se pueden considerar dos pautas principales de argumentación: a) la incorporación al narcotráfico se atenúa apelando a las carencias económicas, a la necesidad de sostener a la familia o al abandono estatal en términos educativos o laborales y b) la incorporación obedece a intereses individuales, como la búsqueda de poder, tener lujos, así como un camino fácil para el ascenso social. Ambas posturas coexisten en los adolescentes, y permiten dar cuenta de la ambivalencia hacia la figura del narcotraficante, culpado por su interés individual que contribuye a la ruptura de la civilidad, pero a la vez exonerado al considerarlo víctima de la desigualdad y de las circunstancias de vida adversas.

\section{Consecuencias de participar en el narcotráfico}

En relación con las consecuencias negativas de estar dentro del narcotráfico, los participantes mencionaron principalmente "la posibilidad de la muerte", tanto por el tipo de actividades como por la traición, y ello no implica sólo la muerte de la persona involucrada, sino que también la familia puede sufrir las represalias. Además de la muerte, perciben el riesgo de ser vigilado, de padecer diversas formas de violencia, incluso el secuestro y la tortura. En este sentido, consideran que estar dentro del narcotráfico implica "vivir con temor", estar nervioso, al grado de no dormir ni divertirse, además de que al entrar, "ya no se puede salir". Otras consecuencias son "tener problemas familiares" e incluso llegar a perder a la familia, ser rechazado socialmente, así como "el riesgo de ir a prisión". Un aspecto que vale la pena resaltar es que dan cuenta de un proceso de trasformación donde la persona empieza a "hacer cosas malas por nada", se acostumbra e incluso hace cosas malas que se empiezan a ver como buenas. Quizá este proceso 
haga alusión al cambio del narcotraficante, para convertirse en una "persona mala".

Respecto a las consecuencias positivas, la mayoría mencionó que no percibía "ningún aspecto positivo", aunque señalaron que desde la perspectiva de los actores, tenía sentido estar en el narcotráfico por "la adquisición de dinero" y, en menor medida, por la posibilidad de conseguir lo que se quiere o elegir qué hacer. En la Figura 1 se resumen las categorías principales identificadas en el estudio.

Figura 1. Categorías principales asociadas con la representación social del narcotráfico

\begin{tabular}{|c|c|}
\hline Categorías & Subcategorías \\
\hline Términos & $\begin{array}{l}\text { Narcotráfico (narcos/tráfico de droga) } \\
\text { zetas/cártel crimen/delincuencia organizada }\end{array}$ \\
\hline \multirow{3}{*}{ Concepto de narcotráfico } & Organizaciones de tráfico de droga \\
\hline & Organización para otros delitos \\
\hline & Organización de personas malas \\
\hline \multirow{6}{*}{ Actores del narcotráfico } & Halcones \\
\hline & Narcotraficantes \\
\hline & Mulas \\
\hline & Personas malas \\
\hline & Sicarios \\
\hline & Capos \\
\hline \multirow{5}{*}{ Motivos para entrar al narcotráfico } & Obtener dinero \\
\hline & Falta de oportunidades (educativas o laborales) \\
\hline & Sacar adelante a su familia \\
\hline & Poder \\
\hline & Conseguir “dinero fácil” \\
\hline \multirow{6}{*}{$\begin{array}{l}\text { Consecuencias negativas de } \\
\text { incorporarse al narcotráfico }\end{array}$} & La muerte \\
\hline & Temor \\
\hline & Hacer cosas muy malas por nada \\
\hline & Problemas familiares \\
\hline & Ser enviado a prisión \\
\hline & Tener que estar alerta \\
\hline \multirow{2}{*}{$\begin{array}{l}\text { Beneficios de estar } \\
\text { en el narcotráfico }\end{array}$} & Ninguno \\
\hline & El dinero \\
\hline
\end{tabular}

Fuente: elaboración propia. 


\section{Conclusiones}

Tal como se encontró en el estudio de Mendoza (2008), los adolescentes emplean términos genéricos para referirse al narcotráfico, como "narco o tráfico de drogas", sin embargo, lo que los diferencia de otros escenarios es que mencionan el nombre concreto de la organización que opera en su contexto social, o como se suele nombrar en la cotidianidad -"El Cártel”-. Si bien ésta realiza múltiples actividades ilícitas (Astorga 2012), no se observa un consenso respecto al uso de términos que hagan alusión a esta diversificación, como “delincuencia o crimen organizado". En estudios previos se encontró que la delincuencia es un elemento central de la representación del narcotráfico (Ovalle 2005; Reyes-Sosa et al. 2015), pero el término "crimen organizado" se suele emplear principalmente en el discurso oficial. La presencia histórica del narcotráfico en este contexto permite que se continúe usando el vocablo, pero se ha comenzado a ligar con el genérico de "delincuencia", para señalar que el fenómeno se ha diversificado, sin que ello implique la adopción completa de los términos técnicos del discurso oficial.

Para los adolescentes, el tráfico de drogas sigue siendo la actividad principal del narcotráfico, pero también lo asocian con otros delitos como el robo, los homicidios o el tráfico de órganos. Si bien en estudios previos el rechazo o la ambivalencia hacia el fenómeno se debe a su relación con las adicciones y la violencia (Reyes-Sosa et al. 2015), un hallazgo importante es que los adolescentes lo perciben como una organización de "personas malas", en especial por los delitos que cometen, que dañan a la gente y ocasionan la muerte. Si bien hay mayor neutralidad hacia la venta de drogas, es la falta de consideración a la vida humana, con tal de conseguir sus intereses (Azaola 2012; Bataillon 2015), lo que lleva a los adolescentes a realizar una evaluación moral de los narcotraficantes.

Aunque las organizaciones del narcotráfico se caracterizan por tener una división sofisticada de funciones (Silva de Sousa 2004), los adolescentes identifican a sus actores como los halcones o vigilantes, los distribuidores de la droga o quienes la trasportan, así como los sicarios y el capo. Dichos personajes ya fueron identificados (Astorga 
2007; Ravelo 2013), pero un hallazgo importante del estudio es que la representación del narcotráfico va a estar moldeada por el grado de cercanía cotidiana con los actores de la organización.

Los personajes de menor jerarquía, como los halcones, dispersos por la ciudad, están más cercanos a los ciudadanos y son más visibles, mientras que el contacto con los distribuidores o trasportadores depende de la identificación de puntos de venta de la droga. Los acontecimientos violentos ocurridos en la comunidad revelan la presencia de los sicarios, pero el conocimiento de ellos está más ligado a las historias narradas acerca de dichos eventos. Se sabe menos de los jefes, de cuya existencia se enteran por los medios de comunicación, pero no los identifican claramente en la experiencia cotidiana.

Otro hallazgo importante es que existen dos formas de ver la actuación de los personajes del narcotráfico en el espacio social: tratan de pasar inadvertidos o se confunden con las "personas normales", lo cual favorecería su movilidad y su inclusión en la comunidad, al no aparentar ser ajenos a ella. Pero, al mismo tiempo, se considera que son "personas diferentes" porque visten distinto, y emplean dispositivos y códigos especiales para sus actividades delictivas, tienen una apariencia intimidante o reivindican una masculinidad violenta; aspectos que limitan la posibilidad de no ser vistos, y que pueden promover que la comunidad los perciba como una alteridad indeseable. Queda pendiente explorar si la forma de presentarse en el espacio social varía con la jerarquía en la organización y con el tipo de delitos que cometen, pero lo que se puede inferir es que los actores del narcotráfico se presentan en el espacio público de varias maneras.

Como ya lo mencionaron Mendoza (2008) o Reyes-Sosa et al. (2015), los adolescentes perciben que diversos actores del narcotráfico practican un estilo de vida que incluye el consumo de drogas, las fiestas o estar con mujeres; lo cual se considera como parte de la narcocultura y se manifiesta en narcocorridos o en películas. Una diferencia encontrada aquí es que los adolescentes piensan que obtener "dinero sucio, matar gente o hacer maldades" se convierte también en una fuente de placer o diversión, lo cual indica que perciben que su comportamiento violento o ilegal está basado en la maldad más que en la patología, y les proporciona un goce; esto representa la evaluación moral que realizan de estos actores, más allá de si la violencia 
y la coerción son empleadas estratégicamente para mantener sus redes de funcionamiento (Raffo y Segura 2015; Silva de Sousa 2004).

A diferencia del estudio de Reyes-Sosa et al. (2015), para los adolescentes el narcotráfico no es un trabajo, sino una actividad que incluso es devaluada, ya que se realiza para obtener "dinero fácil" (Mendoza 2008) o para "adquirir poder". Sin embargo, también coexiste una postura en que la incursión en el narcotráfico se debe a la "falta de oportunidades educativas o económicas”, como lo describió Azaola (2012) al referirse al proceso de desafiliación acelerada de los jóvenes; además de que permite obtener dinero "para sacar adelante a su familia”, lo cual implica justificar la participación delictiva en caso de que se requiera apoyar a los familiares. En este punto vale señalar una diferencia entre las representaciones sociales de jóvenes y de adolescentes, pues mientras para los primeros el narcotráfico puede representar un trabajo, que les permite subsistir y mantener a sus familias, para los segundos es esencialmente algo malo que realizan personas malas.

Por otro lado, las causas identificadas por los adolescentes para la incorporación en el narcotráfico son distintas a las halladas en el estudio de Skrzypiec (2013), donde la participación en el crimen se asocia a la pobre socialización y crianza, el aprendizaje social de familiares involucrados en la organización delictiva, o el mejoramiento de la reputación ante el grupo social de referencia; aunque coincide con la teoría de la tensión respecto a que el acto criminal es una respuesta a la presión generada por la dificultad de acceder a indicadores de éxito, como el dinero o el estatus.

La representación social que construye este grupo de adolescentes acerca del narcotráfico tiende hacia su rechazo, no sólo porque lo consideran delito y no un trabajo, sino por la diversificación de las actividades ilícitas, en especial el secuestro, los homicidios, los robos o la extorsión, que implican una evaluación moral de los narcotraficantes como "personas malas", debido a la posibilidad de generar daños mediante sus actos violentos, no percibidos en su representación como los estratégicos y racionales de una organización. Si bien coexisten posturas respecto a si los actores del narcotráfico son "personas normales" o con una "alteridad violenta”; o si la incorporación se debe a cuestiones estructurales o motivos individuales, en el grupo 
existe un consenso respecto a negar que el narcotráfico tenga aspectos positivos, más allá de los beneficios para los actores en términos de dinero o poder.

Llama la atención que en los adolescentes no se haya manifestado una identificación positiva con el estilo de vida de los narcotraficantes, basado en la fiesta, las mujeres o el consumo de drogas legales e ilegales, tal como ha ocurrido en otros estudios (Mendoza 2008; Reyes-Sosa et al. 2015), puesto que durante la adolescencia las personas pueden experimentar con este tipo de actos "trasgresores" para su edad o para la ley; además de que en México se ven como elementos promovidos por las construcciones contemporáneas de la masculinidad dominante.

De hecho, los adolescentes perciben que el narcotráfico tiene consecuencias negativas para los actores, como el riesgo de morir o de ir a prisión, "vivir con temor", tener problemas con la familia o incluso una trasformación de la persona hacia la "maldad". De esta manera, al construir su representación social del narcotráfico, ellos se identifican como sujetos "buenos" y los actores del narcotráfico son vistos como "malos", sobre todo cuando realizan actos violentos que pueden dañar a la ciudadanía.

Esta representación negativa acerca del narcotráfico tiene diversas funciones e implicaciones. Por un lado, es un fenómeno que se interioriza como parte de la vida cotidiana de la comunidad, y se instaura como un dispositivo que determina y regula las dinámicas de violencia e inseguridad, es decir, legitima el orden social. Por ejemplo, los lugares y las dinámicas permitidos para la venta y el consumo de sustancias se tornan cada vez más clandestinos, aunque no del todo desconocidos para los adolescentes. Lo anterior facilita la construcción de representaciones sociales que no incluyen todas las aristas del fenómeno, lo que permite y legitima la corrupción, porque se ve a los narcotraficantes como personas malas (porque matan o hacen daño físico), pero se omiten otros delitos relacionados directamente con él, como el lavado de dinero. Además, es necesario tomar en cuenta el discurso gubernamental oficial, que tiende a polarizar la imagen del narcotráfico y los narcotraficantes (como personas y actividades unidimensionales, esencialmente malas), y que influye en las representaciones sociales de los adolescentes. 
En el ámbito de la prevención, los elementos mínimos son la promoción de una cultura de la legalidad, la adherencia a la escuela (siempre y cuando ésta se encuentre libre de venta y consumo de sustancias), padres que no se involucran en actividades delictivas y que no censuran o satanizan el uso de drogas, sino que favorecen el consumo responsable de las sustancias legales; así como servicios de recreación, cultura, fomento al deporte, salud y educación de calidad para los adolescentes. Cabe señalar que el papel de las familias, las instituciones sociales y el Estado es fundamental.

En estudios futuros será importante conocer la representación social de las mujeres adolescentes pero, sobre todo, acercarse a este tipo de grupos porque son más vulnerables, no sólo por el proceso de desafiliación acelerada señalado por Azaola (2012), sino porque están más cerca de las organizaciones del narcotráfico en su comunidad. Sin embargo, se recomienda tomar medidas de seguridad para los participantes y los investigadores, en especial en contextos donde hay mucha violencia y censura de los medios de comunicación y de las instancias oficiales sobre la problemática.

\section{Bibliografía}

Astorga, Luis. 2012. Mexico: organized crime politics and insecurity. En Traditional organized crime in the modern world. Responses to socioeconomic change, editado por Dina Siegel y Henk van de Bunt, 149-168. Nueva York: Springer.

Astorga, Luis. 2007. Seguridad, traficantes y militares. El poder y la sombra. México: Tusquets Editores.

Azaola, Elena. 2012. La violencia de hoy, las violencias de siempre. Desacatos 40: 13-32.

Bataillon, Gilles. 2015. Narcotráfico y corrupción: las formas de la violencia en México en el siglo XXI. Nueva Sociedad (255): 54-68. 
Cubides, Olga. 2014. La violencia del narcotráfico en los países de mayor producción de coca: los casos de Perú y Colombia. Papel Político 9 (2): 657-690.

De la O, María Eugenia y Alma Leticia Flores. 2012.Violencia, jóvenes y vulnerabilidad en la frontera noreste de México. Desacatos (38): $11-28$.

Escalante, Fernando. 2012. El crimen como realidad y representación. México: El Colegio de México.

Guerrero, Eduardo. 2016. La inseguridad 2013-2015. Nexos (457): $40-52$.

Guerrero, Eduardo. 2010. La guerra por Tamaulipas. Nexos (392): 1214.

Gundermann, Hans. 2008. El método de los estudios de caso. En Observar, escuchar y comprender. Sobre la tradición cualitativa en la investigación social, coordinado por María Luisa Tarrés, 251-288. México: Facultad Latinoamericana de Ciencias Sociales México, El Colegio de México, Miguel Ángel Porrúa.

Hernández, A. y S. Grineski. 2012. Disrupted by violence: children’s well-being and families' economic, social, and cultural capital in Ciudad Juarez, Mexico. Revista Panamericana de Salud Pública 31 (5): 373-379.

Mendoza, Natalia. 2008. Conversaciones del desierto. Cultura, moral y tráfico de drogas. México: Centro de Investigación y Docencia Económicas.

Ovalle, Lilian. 2005. Entre la indiferencia y la satanización. Representaciones sociales del narcotráfico desde la perspectiva de los universitarios de Tijuana. Culturales 1 (2): 63-89.

Padilla, Héctor. 2012. Ciudad Juárez: militarización, discursos y paisajes. En Vida, muerte y resistencia en Ciudad Juárez. Una aproximación desde la 
violencia, el género y la cultura, coordinado por Salvador Cruz, 105-141. México: El Colegio de la Frontera Norte.

Pontón, Daniel. 2013. La economía del narcotráfico y su dinámica en América Latina. Iconos. Revista de Ciencias Sociales (47): 135-153.

Raffo, Leonardo y José Luis Segura. 2015. Las redes del narcotráfico y sus interacciones: un modelo teórico. Revista de Economía Institucional 17 (32): 183-212.

Ravelo, Ricardo. 2013. Zetas, la franquicia criminal. México: Ediciones B.

Reguillo, Rossana. 2012. De las violencias: caligrafía y gramática del horror. Desacatos (40): 33-46.

Reyes-Sosa, Hiram, Maider Larrañaga-Egilegor y José Francisco Valencia-Garate. 2015. Dependencia representacional entre dos objetos sociales: el narcotráfico y la violencia. Cultura y Representaciones Sociales 9 (18): 162-186.

Secretaría de Salud. 2008. Encuesta nacional de adicciones 2008. http://www.who.int/fctc/reporting/party_reports/mexico_annex1_national_addiction_survey_2008.pdf (12 de febrero de 2016).

Silva de Sousa, Rosinaldo. 2004. Narcotráfico y economía ilícita: las redes del crimen organizado en Río de Janeiro. Revista Mexicana de Sociología 66 (1): 141-192.

Skrzypiec, Grace. 2013. Adolescents' beliefs about why young people commit crime. Australian Journal of Guidance and Counselling 23 (2): 185200.

Stratfor Global Intelligence. 2015a. Mexico’s drug war update: Tamaulipas-based groups struggle. https://worldview.stratfor.com/article/mexicos-drug-war-update-tamaulipas-based-groups-struggle (4 de diciembre de 2017). 
Stratfor Global Intelligence. 2015b. Mexico's disorganized crime. https://worldview.stratfor.com/article/mexicos-disorganizedcrime (4 de diciembre de 2017).

Tong, Allison, Peter Sainsbury y Jonathan Craig. 2007. Consolidated criteria for reporting qualitative research: a 32-item checklist for interviews and focus groups. International Journal for Quality in Health Care 19 (6): 349-357.

Wagner, Wolfgang y Nicky Hayes. 2011. El discurso de lo cotidiano y el sentido común. La teoría de las representaciones sociales. México: Anthropos.

Wagner, Wolfgang, Gerard Duveen, Robert Farr, Sandra Jovchelovitch, Fabio Lorenzi-Cioldi, Ivana Marková y Diana Rose. 1999. Theory and method of social representations. Asian Journal of Social Psychology (2): 95-125. 